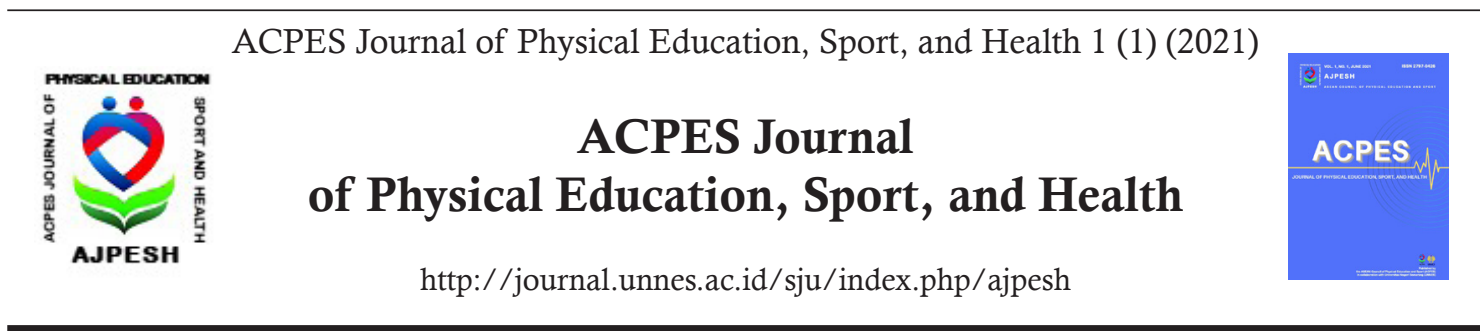

\title{
Impact of Fitspiration Content on Social Media among Followers in Singapore Universities
}

\author{
Jia Hui Shericia Poh ${ }^{1}$, Ho Jin Chung ${ }^{2 \bowtie}$ \\ ${ }^{1}$ Nanyang Technological University, Singapore \\ ${ }^{2}$ National Institute of Education, Nanyang Technological University, Singapore
}

DOI: https://doi.org/10.15294/ajpesh.v1i1.46316

\section{Article Info}

Article History

Submitted 7 January 2021

Revised 24 April 2021

Accepted 11 June 2021

Keywords

Fitspiration, Followers, Social

Media, Singapore Universities

\begin{abstract}
Fitspiration content on social media has been popularized over the last few years, with the intention to influence users to lead healthy and fit lifestyles. The present study aimed to identify the impact of fitspiration content on social media among young adult followers in Singapore. Method: Participants were 124 university students in Singapore who completed a cross-sectional survey. The survey included 16 multiple choice questions, 4 short-answer questions and 8 open-ended questions. Descriptive statistics was adopted for quantitative data and content analysis was utilized for qualitative data. The perceived impact of fitspiration content was explained through three themes: 1) Positive impact of fitspiration content on social media, 2) Negative impact of fitspiration content on social media, and 3) Perceived impact of social media on self. Three other themes were also developed for understanding the conditions influenced by fitspiration content on social media: 1) Evaluation and satisfaction with one's fitness journey, 2) Motivational levels of participants, and 3) Diet restrictions. Results showed that positive impact were experienced by the majority of the participants, whereas some participants experienced negative impacts. It was concluded that fitspiration content on social media does inspire users to become a better version of themselves both physically and mentally. However, it is also dependent on the perceptions of the users and the extent to which they allowed such content to influence them.
\end{abstract}

\section{INTRODUCTION}

Research has shown that people may be easily influenced by traditional media (e.g., television, radio, magazines) and they follow trends in the media to fit in with societal norms and expectations (Perloff, 2009). Tiggemann \& Barbato (2018) has documented the negative impact of the exposure to glorified media images presented in traditional media on women's body dissatisfaction and disordered eating. Since 1999, the media landscape has shifted significantly from traditional media to a more responsive web, known as social media, that allows individuals to post and share content, including staying connected with others (Meraz, 2011).

As of 2017, there are over 2.8 billion social media users in the world, and 1.5 billion of these users are from Asia-Pacific (Shahari, 2019). Young adults aged 18 to 26 years have been reported to be the highest users of social media sites (Perrin,

Correspondence Author:

1 Nanyang Walk, Singapore 637616

e-ISSN 2797-0426

E-mail: hojin.chung@nie.edu.sg 
2015). In Singapore, with a population of 5.6 million in 2017, 4.4 million citizens are active social media users. With over 3.5 million people on Facebook, it is the most popular social media site in Singapore, followed by Instagram with over 1.9 million users (Shahari, 2019), as well as high percentages of users for other social media platforms. Approximately $87 \%$ of Singapore Instagram users and $18 \%$ of Facebook users aged 15 to 24 years old, and 90\% of YouTube users are aged between 16 to 35 years old (Hashmeta, 2018).

The rise of social media has popularized an athletic ideal of the female physique that represents both thinness and visible toning which consists of a more muscular upper body, toned abdomen and stronger lower body (Boepple et al., 2016; Schaefer et al., 2015; Tiggemann \& Zaccardo, 2015). In recent years, a fitness movement known as fitspiration has become popular within social media platforms (e.g., Instagram, Facebook, and Twitter). Fitspiration is a community on social media where individuals post messages and images to inspire people to live healthy lifestyles through exercising and dieting (Boepple \& Thompson, 2016; Jong \& Drummond, 2016). As most of these fitspiration images are of everyday women rather than fashion models (Tiggemann \& Zaccardo, 2015), it may give a sense of attainability to users to achieve similar bodies and lifestyles. Although the goal of fitspiration is to promote healthier lifestyles, it may also lead to unintentional negative consequences on body image (Tiggemann \& Zaccardo, 2015).

Globally, people are investing more time in health and fitness, with an increase of over 20 million members in the global fitness market from 2017 to 2018 (Fitness market size, demographics \& revenue, 2019). According to Deloitte (2018) and the International Health, Racquet \& Sportsclub Association (2018), the Asia fitness industry has also experienced a rapid growth in fitness enthusiasts as it was worth S $\$ 22.8$ billion in 2018. In Singapore, the health and fitness industry has experienced an increase of $5.7 \%$ annually in profits from 2014 to 2018 and is predicted to reach $6.4 \%$ annually between 2018 to 2023 (Aw, 2019). With the health and fitness industry growing at a positive rate, it indicates that more people are committed in health and fitness, which may explain the expansion and popularization of the fitspiration community on social media.

With the rapid growth of social media and the growing population of fitness and health enthusiasts around the world, studies have examined the impact of fitspiration on social media users, especially on women. Fitspiration content on social media is intended to be inspiring healthy behaviors, however, it is also believed to be encouraging an equal amount of inspiration for the pursuit of thinness (Simpson \& Mazzeo, 2017). Research has documented the dangerous effects of viewing thinspiration messages on social media, including increased body dissatisfaction and risks of eating-disorders (Bardone-Cone \& Cass, 2007; Peebles et al., 2012). Hence, if fitspiration content is similar, comparable detrimental effects are highly likely (Simpson \& Mazzeo, 2017).

In Singapore, young adults (aged 23 to 38 years) are the most active social media users (Uy, 2019). Limited studies, however, have examined the positive impact of fitspiration content on social media has on all genders of young adults. Therefore, the increase in social media users and the rising fitspiration movement in Singapore have inspired this study. This study aims to investigate how fitspiration content on social media impact young adult followers in Singapore. 


\section{METHOD}

\section{Participants}

This study was ethically approved by the Institutional Review Board (IRB) at the university. University students $(\mathrm{N}=130)$ were recruited to participate in a crosssectional survey for five-weeks from mid-August to September 2019. Convenience sampling procedure (Waterfield, 2018) is employed for the survey collection. It is a method commonly used in most studies that utilized surveys to examine the relationship between social media and fitspiration or thinspiration (Raggatt et al., 2018; Perrault et al., 2019; Fardouly et al., 2015; Ho et al., 2016). Participants completed the survey via Google Forms non-anonymously. Eligible participants fell in the age range of 19 to 26 years old and were enrolled in a university based in Singapore. Prior to the survey, participants were excluded from completing the survey if they did not meet the eligibility criteria (Lavrakas, 2011). Participants were first informed of the purpose of the study, their non-obligatory decision to participate in the survey and the confidentiality of their personal details and answers. Participants will only attempt the survey with consent. Out of all the responses recorded, 6 participants were excluded because they did not meet the eligibility of the study. No incentive or reimbursement was offered for participation. Table 1 indicates participant characteristics.

Table 1. Participant characteristics

\begin{tabular}{cccccc}
\hline Age (Years) & $\mathrm{N}(\%)$ & Gender & $\mathrm{N}(\%)$ & University & $\mathrm{N}(\%)$ \\
\hline 19 & $2(1.6 \%)$ & Male & $\begin{array}{c}44 \\
(35.5 \%)\end{array}$ & $\begin{array}{c}\text { Nanyang Technological University } \\
\text { (NTU) }\end{array}$ & $65(52.4 \%)$ \\
20 & $1(0.8 \%)$ & Female & $\begin{array}{c}79 \\
(63.7 \%)\end{array}$ & $\begin{array}{c}\text { National University of Singapore } \\
\text { (NUS) }\end{array}$ & $20(16.1 \%)$ \\
21 & $5(4.0 \%)$ & $\begin{array}{c}\text { Prefer not } \\
\text { to say }\end{array}$ & $1(0.8 \%)$ & $\begin{array}{c}\text { Singapore Institute of Management } \\
\text { (SIT) }\end{array}$ & $12(9.7 \%)$ \\
22 & $20(16.1 \%)$ & & & $\begin{array}{c}\text { Singapore Management University } \\
\text { (SMU) }\end{array}$ & $1(0.8 \%)$ \\
23 & 48 & & & $\begin{array}{c}\text { Singapore University of Social Scien- } \\
\text { ces (SUSS) }\end{array}$ & $15(12.1 \%)$ \\
& $(38.7 \%)$ & & & $\begin{array}{c}\text { Singapore University of Technology } \\
\text { and Design (SUTD) }\end{array}$ & $0(0.0 \%)$ \\
24 & 21 & & & Others & $11(8.9 \%)$ \\
25 & $(16.9 \%)$ & & & & \\
26 & $(15.3 \%)$ & & & &
\end{tabular}

\section{Data Collection}

A pilot test of the survey was conducted on the principal investigator and the co-investigator's associates, and feedback was received to improve clarity and execution of the questions. The sample size for the pilot test was dependent on the ability of the participants to offer adequate feedback about the elements that are assessed for accessibility (Rutherford-Hemming, 2018). Pilot tests refer to a study that is done to test the feasibility of a method that will be used in a future larger study, which can be very beneficial in providing justifications on procedures (Rutherford-Hemming, 2018). The total time to complete the survey took approximately 10 minutes. A secure, web-based site, Google Forms, was utilized to collect and manage data from the participants. The following sections were covered in the survey: 


\section{Demographic attributes and engagement in physical activity}

Demographic characteristics were collected consisting of age, gender, and university enrolled. Participants also reported the approximate number of days they engaged in physical activity per week, as well as the number of hours in a day they performed physical activity.

\section{Social media usage}

Participants indicated the types of social media they frequent by selecting one or more choices: Facebook, Instagram, Pinterest, Snapchat, Twitter, Tumblr, YouTube, and/or Others (indicate the social media platform). Participants also reported the approximate number of hours they spend on social media per day. In addition, participants indicated the types of content they engage in social media by selecting one or more choices: Beauty, Educational content, Fashion, Food, Health \& Fitness, Travel and/or Others (indicate content). Yes/No items enquired if participants followed accounts that focus on fitspiration content.

\section{Perception of fitness influencers on social media}

Studies have shown that viewing fitspiration imagery develop greater body dissatisfaction and an increased negative mood (Tiggemann \& Zaccardo, 2015; Prichard et al., 2017). Influenced by previous research (Tiggemann \& Zaccardo, 2015; Robinson et al., 2017), 6 images of fit and muscular fitness influencers of 3 women and 3 male influencers were utilized in the survey to analyze participants' perception of such images. All images were sourced from public Instagram accounts. These influencers are the ambassadors for various fitness companies, such as Gymshark and MyProtein. One of the influencers is the owner of a fitness application known as "SWEAT". Participants reported the number of times per day they view images similar to the 6 images on a 7-point measure: Not at all, 1 to 2,3 to 4,5 to 6,7 to 8, 9 to 10, all the time. Participants also indicated their feelings after viewing the 6 images: Impressed, Motivated, Jealous, Lower self-esteem, Others (indicate feeling). Yes/No items asked if the participants were insecure of their bodies after viewing the 6 images, and comparison of their bodies with the 6 images (Figure 1).

\section{Comparison of own's physique with others on social media}

Yes/No items asked if participants compare their own bodies with others on social media. Following that, participants indicated their actions after comparison by selecting one or more choices: Start working out, Increase duration\& intensity of work-out sessions, Start dieting, Never been influenced by social media to change the way I look (if participants answered "no" for the previous question), and/or Others (indicate action).

\section{Self-evaluation and perception of bodies}

To better understand how participants perceive their bodies, they indicated the number of times they hated/disliked their bodies in the mirror per month on a 7-point measure: Not at all, 1 to 2, 3 to 4, 5 to 6, 7 to 8, 9 to 10, all the time. Yes/No items enquired if participants wish to change any parts of their physical appearance and they indicated the part(s) they wished to change. 


\section{Satisfaction with own's physique}

To analyze if participants were satisfied with their bodies, they indicated if they were or were not happy with the way their bodies look currently, and reasons were stated if participants were not happy.

\section{Perceived influence of Fitspiration content on social media}

According to Gerbner (1969), there is the existence of cultural indicators in society where a change in a message mass-production will lead to a shift in the common symbolic environment that provides the public purpose and sense of direction to human activity. With social media becoming a norm in today's society, the awareness of social media is publicly held and this makes collective thought and action possible. Hence, there exists a degree of influence of fitspiration content on social media on those who consume such content regularly. As this study focuses on examining the impacts of fitspiration content on social media on young adult followers, participants indicated the extent to which they perceive fitspiration content on social media has a positive and negative impact on themselves or on others on a scale of 1 to 5 , respectively. They were also asked to elaborate on their perceived impacts based on the number of scale they chose. Participants also reported the extent to which social media plays a role in influencing their perception of their own bodies on a scale of 1 to 5 , with elaboration for their choice.

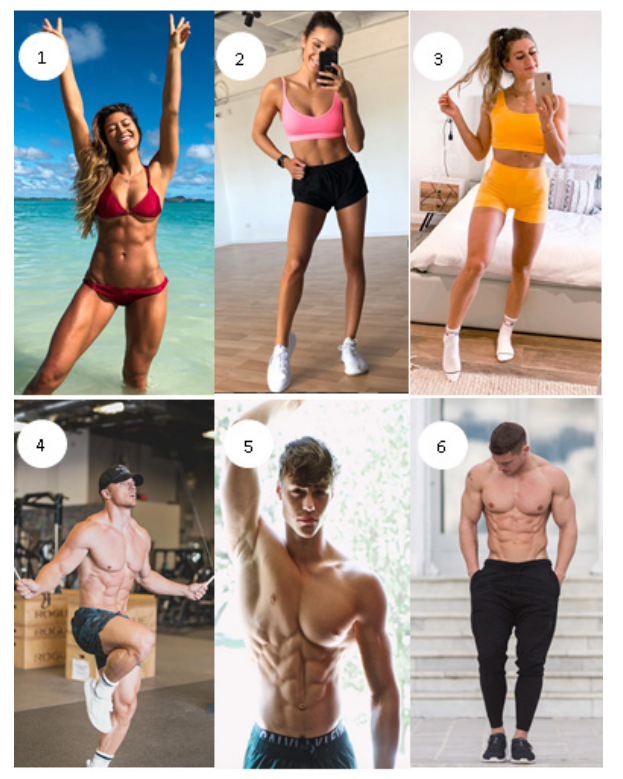

Figure 1. Images of fitness influencers on social media

Note: 1. Karina Elle (Instagram: 1.6m followers; Gymshark athlete), 2. Kayla Itsines (Instagram: 11.8m followers; Founder of SWEAT), 3. Natacha Oceane (Instagram: 670k followers, YouTube: 556k subscribers; Gymshark athlete), 4. Steve Cook (Instagram: $2.5 \mathrm{~m}$ followers, YouTube: $1.25 \mathrm{~m}$ subscribers; Gymshark athlete), 5. David Laid (Instagram: 1.3m followers; 921k subscribers; Gymshark athlete), 6. Matt (Instagram: 371k followers; YouTube: 960k subscribers; Gymshark \& MyProtein athlete)

Conditions influenced by fitspiration content on social media among participants Cultivation theory stated that the mass production and sharing of messages 
reconstruct selected personal perspectives into broad public perspectives (Gerber, 1969). In this case, the constant circulation of fitspiration content on social media has the potential to change a user's perspective into the perspectives of the public, hence influencing them to carry out certain actions and activities that are communal. Therefore, Yes/No items asked if participants are motivated or pressured to start exercising and/or dieting when they view fitness content on social media in the survey. If participants indicated yes, they indicated the reasons by selecting one or more choices: To achieve bodies that are similar, To be healthy, To lose weight/fats, To become stronger/gain muscles, Because peers are fitter or skinner than me and/or Others (indicate reason). Following Raggatt et al. (2018), open-ended questions were asked for self-expression from participants to better understand the conditions influenced by fitspiration content on social media among the participants.. Open-ended questions helps to limit bias due to perceived knowledge of the researcher's understanding of the impacts of fitness content on social media. Participants who indicated "no" do not have to answer the questions in table 2.

Table 2. Open-ended guiding questions in the survey

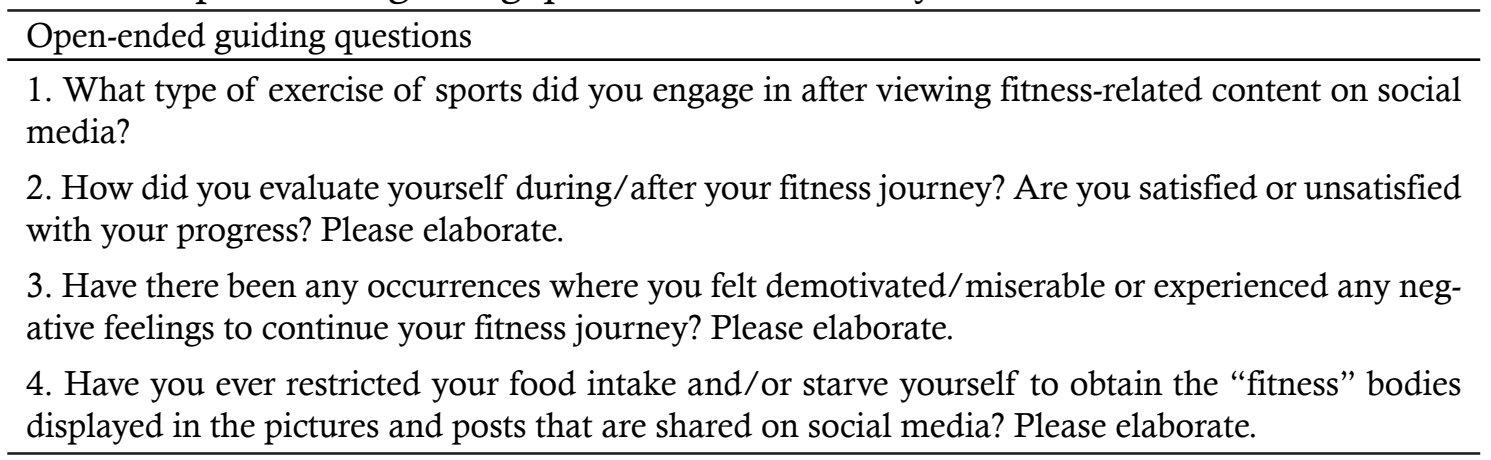

\section{Data Analysis}

Descriptive statistics comprises a mathematical summarization of a set of data which was applied to interpret the quantitative data for this study (Schreiber, 2012). Quantitative data was used to determine the percentage of participants who engaged in physical activity, the types of content they viewed on social media, percentages of those who follow fitspiration accounts, how they felt after viewing fitspiration content on social media, the way they evaluated their bodies, and the reasons for their motivation to exercise.

Content analysis (Hsieh \& Shannon, 2005) was adopted to analyze the qualitative data on the effects of fitspiration content on social media among the participants and their perceived influence of fitspiration content on social media for this study. This analysis is a frequently used method for analyzing a broad range of textual data, such as responses to open-ended questionnaire items, narratives, and interview questions (Julien, 2012). More specifically, directed content analysis (Table 3) was applied for analysing the data, where the themes were derived prior to existing theory or research (Goodyear, Armour \& Wood, 2019; Raggatt et al., 2018) and during data analysis (Potter \& Levine-Donnerstein, 1999). Data were collected via open-ended questions, followed by intended questions about the predetermined categories (Hsieh \& Shannon, 2005). 
Table 3. Suggested phases for directed content analysis

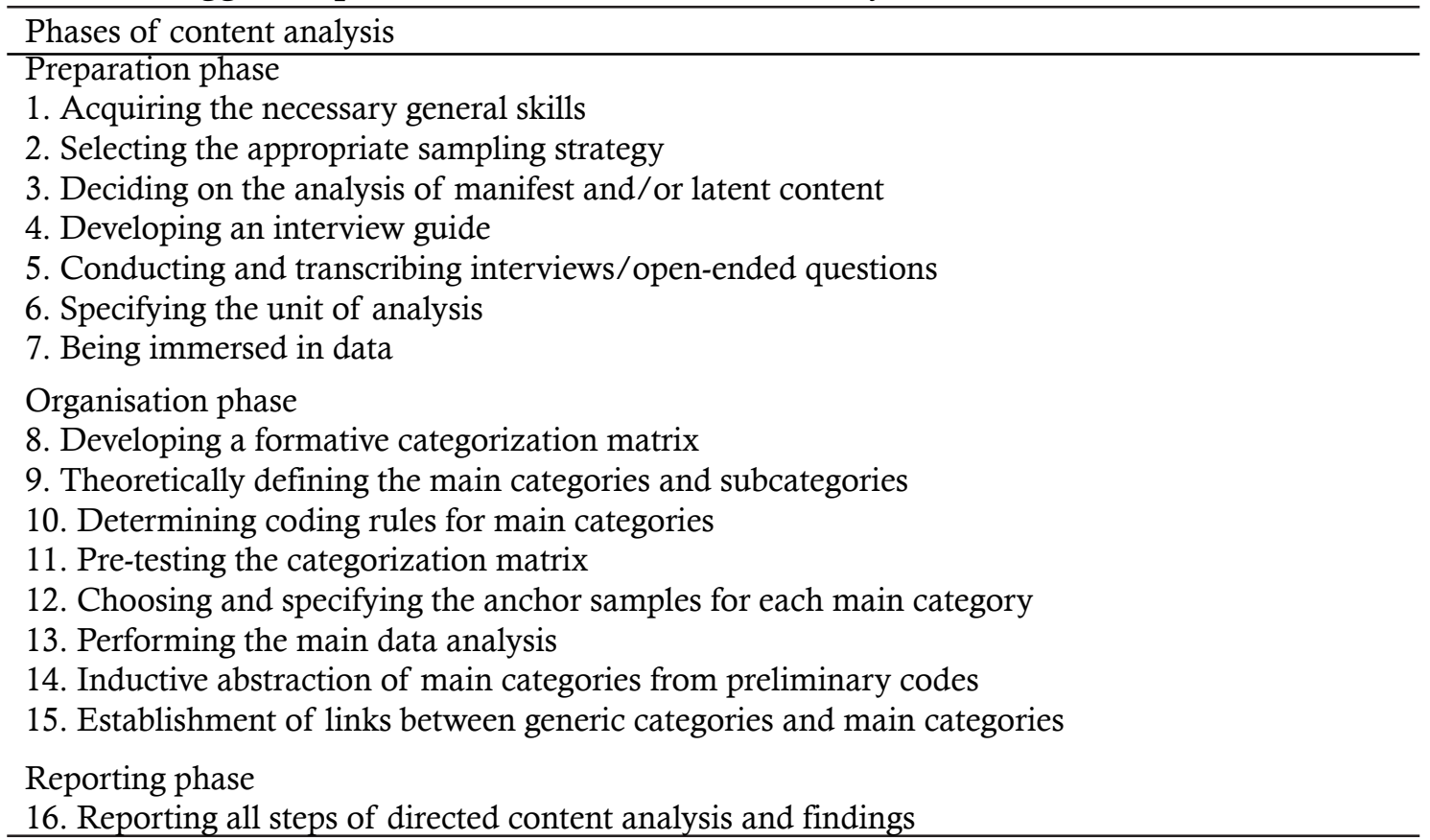

\section{RESULT AND DISCUSION}

\section{Perception of fitness influencers posts on social media}

Participants were assessed on the number of times they viewed similar images of fitness influencers on social media (as seen in Figure 1 in "Data Collection"). Majority of the participants view such images 1 to 2 times per day $(n=45,36.3 \%)$ on social media. $8.9 \%(n=11)$ of all the participants $(n=124)$ do not view similar fitness influencers images on social media at all. On the other hand, $16.9 \%(n=21)$ of all the participants $(n=124)$ view similar images on social media all the time, with $14.3 \%$ $(n=3)$ of these 21 participants not following fitspiration accounts.

Most of the participants reported feeling impressed $(n=82,66.1 \%)$ after viewing the fitness influencers pictures (as seen in figure 1 in "Data Collection"), followed by feeling motivated $(n=61,49.2 \%)$, feelings of jealousy $(n=27,21.8 \%)$, having lower self-esteem $(n=15,12.1 \%)$, and having neutral feelings $(n=14,11.3 \%) .36 .3 \%(n=45)$ of the participants experienced feelings of insecurities after viewing the pictures, and $52.4 \%(n=65)$ of them found themselves comparing their own bodies with the bodies on the images (Note: Participants were able to choose multiple options for this question). These results are similar to a study which have found that although engaging in fitspiration content does result in women feeling inspired to work-out and eat healthier, it also led to increased body resentment in some of them (Tiggemann \& Zaccardo, 2015).

\section{Self-comparison with others on social media}

$61.3 \%(n=76)$ of the participants reported comparing themselves with others on social media. A study done by Robinson et al. (2017) found that comparisons with idealised images on social media tend to result in women feeling inadequate about their own bodies, leading to body dissatisfaction. Therefore, it is not surprising that 
the majority of the participants $(n=52,41.9 \%)$ in this study reported that they would start to work-out when they compared themselves with others on social media, followed by dieting $(n=33,26.6 \%)$, and increasing the duration and intensity of their work-out sessions $(n=28,22.6 \%)$ (Note: Participants were able to choose multiple options for this question).

\section{Self-evaluation and perception of physical appearance}

The majority of the participants $(n=45,36.3 \%)$ reported disliking the way their bodies look in the mirror 1 to 2 times per month, and $54.5 \%(n=18)$ of these 54 participants follow fitspiration accounts. $78.6 \%(n=11)$ of the participants who reported that they disliked the way their bodies looked in the mirror all the time $(n=14,11.3 \%)$ follow fitspiration accounts. Interestingly, $26.6 \%(n=33)$ of the participants did not experience any dislike for their bodies when they looked in the mirror over the past month, with $54.5 \%(\mathrm{n}=18)$ of these 33 participants following fitspiration accounts on social media.

Most of the participants ( $n=92,74.2 \%)$ have a desire to change a part or parts of their physical bodies. The top 3 parts that participants want to change are abdominals $(n=27,21.8 \%)$, followed by thighs $(n=20,16.1 \%)$, and lower fat mass $(n=15,12.1 \%)$.

\section{Satisfaction with own's physique}

All the participants were asked if they were satisfied with the way their bodies look currently. The majority of the participants $(n=67,54.0 \%)$ are not happy. Most of the participants associate being happy with the way their bodies look with the need to lose weight and/or fats: "No, I am not happy because for some reason, I just gain more weight despite exercising and eating with care." (Female, 21), "I don't like how my body looks, as it is still rather chubby and undesirable to me." (Male, 25), and "No, I am not happy because I am visibly fatter compared to others (given the same height)." (Female, 23). Participants may feel dissatisfaction with their bodies due to the exposure of media messages that promotes unrealistic body standards (Richard, 2014). Hence, imposing on them the idea that they need to lose weight to meet such standards. $41.1 \%(n=51)$ of the participants are happy with how their bodies look. The remaining $4.8 \%(n=6)$ of the participants reported feeling neutral about the way their bodies look.

\section{Perceived influence of fitspiration content on social media}

Three key themes emerged regarding the perceived influence of participants on fitspiration content that is posted on social media: 1) Positive impact of fitspiration content on social media, 2) Negative impact of fitspiration content on social media, and 3) Perceived impact of social media on self.

\section{Positive impact of fitspiration content on social media}

On a scale of 1 to 5 , a small number of participants $(n=4,3.2 \%)$ selected scale 5 for the extent that fitspiration content on social media has positive effects on its users. Majority of the participants $(n=61,49.2 \%)$ selected scale 4 . Most of the reasons for their scale selection are similar as participants expressed that fitspiration content on social media helps to motivate others to lead a healthy lifestyle and to serve as a reminder to stay active: "I believe it is a win-win situation for both the people posting 
and viewing them, as you are motivated and motivating others at the same time." (gender unclassified, 23), and "We spend a lot of time on social media so in some way or another they can impose their fitness journey or progress on us. Also, people have natural insecurities in some way, so they might want to work hard to achieve a nice body. Appearance in this day and age is important to certain groups of people (age) so to make themselves feel better, they can indulge in gym work to get a nicer appearance." (Male, 25).

Participants ( $\mathrm{n}=43,34.7 \%)$ who selected scale 3 , followed by those who selected scale $2(n=15,12.1 \%)$ stated similar reasons. Fitspiration content on social media is perceived to motivate people to exercise, but it serves as a motivation only because participants want to achieve the bodies of fitness influencers on social media: "Motivates people to want to look like them and work hard for their desired physique and build healthy eating/dieting habits." (Male, 25), and "Might motivate others to want to work-out more and achieve what these fitspo influencers have (physique, strength, body, etc.)." (Female, 23). Only 1 participant selected scale 1 which indicated that fitspiration content on social media has the least positive impact on users.

\section{Negative impact of fitspiration content on social media}

On a scale of 1 to 5 , a small percentage of the participants ( $n=6,4.8 \%$ ) selected scale 5 which meant they believed that fitspiration content on social media has a negative impact on users to a large extent. The main reason for their selection is because they felt that fitspiration content on social media causes people to be obsessed with the idea of achieving the ideal body: "Makes people feel that ideal body image is such, causing people to feel unhappy about their own bodies even when it is not in a very bad condition." (Female, 26).

The majority of the participants selected scale $3(n=42,33.9 \%)$, followed by selection of scale $4(n=38,30.6 \%)$. The reasons for their scale selection are relatively the same which included comparisons, lower self-esteem, and exerting unnecessary pressure on users: "The only negative impact it could have on people is being overly focused on getting the ideal body by engaging in unhealthy means." (Female, 23) and "Reflects on how an individual's body shape is bad compared to those on social media, leading to undesirable consequences such as starving or taking pills to achieve slender body." (Female, 23)

Participants who selected scale $2(\mathrm{n}=24,19.4 \%)$ expressed two different types of perceptions in regard to the negative impact that fitspiration content on social media has on people. Some of the participants stated that fitspiration content on social media results in unrealistic body standards, for example, "set unrealistic standards which could induce esteem issues in some." (Female, 26). On the other hand, some of the participants felt that individuals should know that pictures posted on social media could be edited, hence, it is dependent on the perceptions of the individuals with regards to how negatively social media can influence them. For example: "Everyone's body is different and reacts differently to work-out so it may not be an accurate result even if I followed the work-out on social media." (Male, 23), and "Maybe the pictures are photoshopped, so it's quite hard to attain such nicely toned muscles and look like that all day." (Male, 24)

Participants who selected scale $1(\mathrm{n}=14,11.3 \%)$ reported that fitspiration content on social media should not have much of a negative impact on people because 
most of them believed that it is dependent on one's perception of how they perceived the impact. Participants stated that: "I don't think that people should have a negative impact. It shows how low their self-esteem is." (Gender unclassified, 23), and "They (fitness influencers) are just a bunch of show-offs." (Male, 24)

\section{Perceived impact of social media on self}

On a scale of 1 to 5 , in terms of how social media has an impact on participants, $4.0 \%(n=6)$ of the participants selected scale 5 , and $30.6 \%(n=38)$ selected scale 4 . The individuals have stated both positive and negative reasons for their scale selection: "It motivates me to continue exercising to stay fit." (Female, 23), and "Images are both explicitly and implicitly sending out messages of what your body should look like and what gets the most likes/attention. It makes us question our different yet natural bodies." (Female, 23).

Majority of the participants $(n=42,33.9 \%)$ selected scale 3 for the degree of extent that fitspiration content on social media has an impact on them. A proportion of the participants reported comparison as one of the factors that fitspiration content on social has an impact on their body image: "I guess it does influence to a certain extent. Humans tend to compare \& when we see posts with lots of likes, we will tend to compare \& hope to be the same." (Male, 24).

Participants also feel that social media serves as a motivation for them to lead healthy lifestyles and provided them with relevant information on health and fitness. Such reasons are similar to those participants who selected scale $2(n=24,19.4 \%)$, and of those $(n=14,11.3 \%)$ who selected scale 1 . Participants felt that social media provided them an opportunity to: "To be more motivated to work-out but not necessarily to achieve the body images on Instagram. It's more of a reminder to keep fit and healthy. But I feel younger girls especially might see it as an 'ideal body type' and feel bad about their own bodies, which can influence feelings of depression/anxiety etc." (Female, 22), and "Use social media as a form of educative platform to achieve the standards I set for myself instead of what is marketed as 'necessary' by society. Focuses on well-being and motivational platforms." (Female, 26).

\section{Conditions influenced by fitspiration content on social media}

Engaging in fitspiration content on social media may lead to some users being too consumed with fitness which could become detrimental for their well-being (Dahl, 2013; Hausenblas, 2015). The majority of the participants ( $n=86,69.4 \%)$ felt motivated or pressurized to start exercising and/or dieting when they view fitspiration content on social media. Out of these 86 participants, $75.6 \%(n=65)$ follow fitspiration accounts. The remaining $24.4 \%(n=21)$ do not follow fitspiration accounts, but they still felt the pressure or motivation to exercise due to the exposure of fitspiration content on social media.

The majority of these 86 participants $(n=64,74.4 \%)$ have the desire to lose weight/fats, $70.9 \%(n=61)$ aimed to be healthy, $69.8 \%(n=60)$ wished to become stronger/gain muscles, $25.6 \%(n=22)$ hoped to achieve bodies that are similar to the fitness influencers on social media and $20.9 \%(n=18)$ felt the need to exercise because their peers are fitter and/or skinner than them (Note: Participants were able to choose multiple options for this question).

Responses from 86 participants who completed the open-ended questions cor- 
responding to feeling pressurized/motivated to exercise or diet after viewing fitspiration content on social media were analyzed. Three key themes emerged to explain the conditions influenced by fitspiration content on social media among participants: 1) Evaluation \& satisfaction with one's fitness journey, 2) Motivational levels of participants, and 3) Diet restrictions.

\section{Evaluation and satisfaction with one's fitness journey}

$54.7 \%(n=47)$ of the 86 participants were satisfied with their fitness journey after viewing fitspiration content on social media because social media provided them with relevant skills and information regarding health and fitness. For example, "I am satisfied. There is useful content available online for reference" (female, 26). Most of them evaluated themselves through their performance levels in their sports or the gym. Although some of the participants stated that they are satisfied with their progress, they believed that more can be done: "I am satisfied, but there is a long way more to go." (Male, 24). 32.6\% $(\mathrm{n}=28)$ are unsatisfied with their fitness journey after viewing fitspiration content on social media. The majority of them are unsatisfied due to feeling demotivated to exercise and slow progression: "I am unsatisfied because there are times where I will lose motivation." (Female, 23), and "Not yet satisfied, because the progress is too slow." (Female, 23). The remaining $12.8 \%(n=11)$ of the participants did not state their satisfaction levels, but they did mention how they evaluated themselves during/after their fitness journey, which was usually through the amount of weight that they have gained/lost: "I evaluate myself through my weight gain/loss.." (Female, 23).

\section{Motivational levels of participants}

The majority of the participants $(n=50,58.1 \%)$ experienced feeling demotivated to continue their fitness journey. Participants usually felt demotivated because they felt that their fitness progression is slow or stagnant, for example, "There will be times where no progress can be seen, due to fatigue and cannot push further." (Male, 24).

Subsequently, participants reported dieting as a major factor in their fitness journey that caused them to feel demotivated and that they lacked the discipline to continue dieting: "Demotivated yes, because I love to eat so once I break my clean diet, that's the end of it. It's very hard to start again. I feel like it comes with a lack of discipline as well ... I want to look a certain way, but I don't have the full drive to do it and just be 'whatever' about the way I look" (Female, 23).

Participants also reported feeling demotivated because they associated their results with changes in their weight: "Yes I feel demotivated when I don't see any results, or when I gain fats/weight." (Female, 23). 41.9\% $(n=36)$ reported that they do not have any occurrences where they felt miserable or demotivated to continue their fitness journey. The main reason for staying motivated was because most of these participants enjoyed working out: "I'll never stop wanting to be active and fit if I have the liberty to do so, it's my hobby." (Female, 23).

\section{Diet restrictions}

The majority of the participants $(n=50,58.1 \%)$ have underwent diet restrictions or starved themselves before due to feeling pressurized/motivated because of fitspi- 
ration content posted on social media. Limiting the amount of carbohydrates intake was one of the major factor for dieting, even though some of them have claimed that they were unhappy from cutting out carbohydrates from their diets: "I tried to restrict fried food and carbs intake" (Female, 23); and "Yes I have restricted my food intake by taking in less carbs and it was miserable." (Female, 21). It has also become apparent that participants were counting their calories to lose weight/fats: "Yes, in the sense that I count calories more cautiously and got rid of excess sugar/ calories intake in the diet." (Female, 22). These results can be supported by a study done by Tiggemann \& Zaccardo (2018) which have examined that users who view fitspiration content may immerse themselves in unhealthy behaviors related to diet or exercise with hopes of achieving the fit ideal body.

\section{Discussion}

The aim of this study sought to examine the impact of fitspiration content on social media among young adult followers who are currently studying in Singapore universities. Results suggest that the more days participants engaged in physical activity, the more engaged they are in viewing fitspiration content and following fitspiration accounts. It is possible that the more frequent participants view fitspiration content, the more susceptible they are to exercise due to the constant engagement with fitspiration content. This is supported by a study that identified a preliminary link between viewing fitspiration images and a greater desire to exercise, compared to participants who viewed travel images (Tiggemann \& Zaccardo, 2015).

The majority of the participants reported experiencing a positive impact from viewing fitspiration content on their social media platforms. The finding that participants was motivated to exercise and/or to eat healthy after viewing fitness influencers images on social media is consistent with a study which reported that individuals experienced positive benefits from the use of social media which consisted of motivation to exercise and having access to fitspiration content (Raggatt et al., 2018). Fitness influencers on social media were treated as motivators and inspirations for participants to maintain a healthy lifestyle. However, it is apparent that some of the participants associated fitness as having to undergo strict dieting and work-out regimes to look and achieve the bodies of these fitness influencers. This aligns with a study that reported users rationalizing their efforts to look fit to improve their health, hence suggesting they believe that only by looking a certain way can they achieve optimal health (Raggatt, et al., 2018). Dieting and exercising for appearance reasons rather than for health reasons has been associated to greater body resentment, eating disorders and lower self-esteem among women (Goncalves \& Gomes, 2012; Prichard et al., 2017).

A small percentage of the participants responded feeling negative emotions, including being jealous and having lower self-esteem. Feelings of negative emotions after viewing fitspiration imagery on social media is not surprising as a great amount of research have reported that women experienced increased body dissatisfaction, negative moods and lower appearance self-esteem after engaging in fitspiration content on social media (Robinson et al., 2017; Tiggemann \& Zaccardo, 2015; Lewallen \& Behm-Morawitz; 2016). Male participants constituted a large percentage of those who felt jealous after looking at the fitness influencers pictures.

Participants provided explanation for their views on the negative impact fitspi- 
ration content on social media have on them. Feelings of insecurities, self-criticism and body dissatisfaction among the participants is consistent with previous studies that documented the negative effects of viewing fitspiration images on the body image of social media users (Raggatt et al., 2018; Tiggemann \& Zaccardo, 2015; Wiklund et al., 2019). The finding that participants reported comparison as a negative impact aligns with a study which suggested that social comparison theory can be seen as a trait variable which suggest that women experienced higher body dissatisfaction due to comparing themselves with fitspiration images on social media (Robinson et al., 2017).

One key theme that constantly emerged from participants was that fitspiration content on social media present unrealistic standards for people to conform to. It seems that although some of the participants do aspire to achieve bodies similar to those of the fitness influencers, they were aware that it may be unrealistic to achieve. Previous research has demonstrated that social media was portrayed as a powerful arena that set high and elusive fitness goals for users to achieve (Wiklund et al., 2019). It is also identified that majority of the participants are influenced by fitness influencers on social media to work-out and diet. It can be perceived that fitness influencers on social media have the power to influence their followers because their followers believe and follow what they share on their social media platforms. This can be supported by a study which found that followers preferred to follow recommendations by their favourite influencers because they are often perceived by their followers as being more trustworthy and compelling (Talaverna, 2015).

A quarter of the participants reported not experiencing any negative body image when they viewed themselves in the mirror. Interestingly, half of these participants reported following fitspiration accounts. This finding contradicts previous studies that have demonstrated an association between viewing fitspiration imagery and body dissatisfaction among users (Deighton-Smith \& Bell, 2018; Simpson \& Mazzeo, 2017; Tiggemann \& Zaccardo, 2015). Participants addressed that they are currently satisfied with the way their bodies look and they did not feel the need to be affected by external influences.

\section{Limitations and Future Study}

This study was not without limitations. Firstly, although the survey questions were referenced and adapted from related studies (Tiggemann \& Zaccardo, 2015; Robinson et al., 2017), the questions were created by the author which may hinder the reliability ad validity of the present study. Secondly, collection of more comprehensive qualitative responses from the participants was impeded due to the study design. Less than half of the participants were males, which suggest that more exhaustive data can be collected and compared with female participants if there were more male participants. Thirdly, the study only focused on the consumption of fitspiration content of the participants. Participants' engagement on their social media platforms should have been assessed too (eg., posting of fitspiration content on social media), so as to better understand if such engagement on social media will also have an impact on the participants. Fourthly, this study included participants who do not view or follow fitspiration content on social media. Only focusing on participants who view and follow fitspiration content on social media may have resulted in more in-depth qualitative data collection and analysis. Lastly, participants were asked if 
they wished to change any part(s) of their body and three-quarter of the participants reported having the desire to change. However, there was a lack of follow-up on this question (e.g., reasons for change) which could have been significant for the study.

In view of future research, researchers can consider examining the significance of fitspiration content on YouTube among users. The top three social media platforms assessed by the participants included Instagram, YouTube and Facebook. However, studies examining the relationship of fitspiration content and social media are usually focused on Instagram or Facebook (Cohen et al., 2017; Lee et al., 2015; Tiggemann \& Zaccardo, 2018). Additionally, future research could also consider mental health factors (eg., eating disorders, depression, anxiety) as some research have identified mental health factors as one of the effects of viewing idealized images on social media (Alberga et al., 2018; Deighton-Smith \& Bell, 2018; Raggatt et al., 2018). Finally, further research examining the impact of fitspiration content on social media can be done predominantly on men, since previous research have mostly involved women only (Baker et al., 2019; Cohen et al., 2017; Prichard et al., 2017).

\section{CONCLUSION}

The present study identified that fitspiration content on social media does what it intends - to inspire users to lead healthier lifestyles. Positive impacts were experienced by a majority of the participants. However, there seems to exist a belief among some participants that optimal health and fitness is reached only when they achieve similar bodies as the fitness influencers on social media. On the contrary, this study has also demonstrated that participants experienced negative impacts that are similar to the results of other related research. Participants also reported being aware that some fitspiration content on social media does provide unrealistic fitness goals for users. In sum, the impact of fitspiration content on social media is dependent on the perceptions of the participants and how they allowed such content to influence them. As the use of social media has become fundamental in today's modern society, it is recommended for future research to continue examining the extent of engaging in fitspiration content on social media among followers, in relation to their mental and physical health.

\section{REFERENCES}

Aw, C. W. 2019. Fitness industry shapes up: Gyms and fitness studios are having a good run. Retrieved from https://www.sgsme.sg/news/ fitness-industry-shapes-gyms-and-fitness-studios-are-having-good-run

Alberga, A. S., Withnell, S. J., \& Ranson, K. M. V. 2018. Fitspiration and thinspiration: a comparison across three social networking sites. Journal of Eating Disorders, 6(1). https://doi.org/10.1186/s40337-018-0227-x

Baker, N., Ferszt, G., \& Breines, J. G. 2019. A Qualitative Study Exploring Female College Students Instagram Use and Body Image. Cyberpsychology, Behavior, and Social Networking, 22(4): 277-282. https://doi.org.10.1089/cyber.2018.0420

Bardone-Cone, A., \& Cass, K. 2007. What does viewing a pro-anorexia website do? An experimental examination of website exposure and moderating effects. (Clinical report). The International Journal of Eating Disorders, 40(6): 537-548. https://doi. org/10.1002/eat.20396

Boepple, L., Ata, R., Rum, R., \& Thompson, J. 2016. Strong is the new skinny: A content analysis of fitspiration websites. Body Image, 17: 132-135. https://doi.org/10.1016/j.bodyim.2016.03.001

Boepple, L., \& Thompson, J. 2016. A content analytic comparison of fitspiration and thinspiration websites. International Journal of Eating Disorders, 49(1): 98-101. https://doi.org/10.1002/eat.22403

Cohen, R., Newton-John, T., \& Slater, A. 2017. The relationship between Facebook and Instagram appearance-focused activities and body image concerns in young women. Body Image, 23: 183-187. https://doi.org/10.1016/j.bodyim.2017.10.002

Dahl, M. 2013. New Pinterest fad may fuel unhealthy fitness obsession. Retrieved from http://www.today.com/health/new-pinterest-fadmay-fuel-unhealthy-fitness-obsession-6C10866502

Deighton-Smith, N., \& Bell, B. 2018. Objectifying Fitness: A content and thematic analysis of \#Fitspiration images on social media. Psychology of Popular Media Culture, 7(4): 467-483. https://doi.org/10.1037/ppm0000143 
Fardouly, J., Diedrichs, P. C., Vartanian, L. R., \& Halliwell, E. 2015. The Mediating Role of Appearance Comparisons in the Relationship Between Media Usage and Self-Objectification in Young Women. Psychology of Women Quarterly, $39(4): 447-457$. https://doi.org/10.1177/0361684315581841

Fitness market size, demographics \& revenue 2019 [+ Research Report]. 2019. Wellness Creative Co. Retrieved from https://www. wellnesscreatives.com/fitness-market/. January 9.

Gerbner, G. 1969. Toward "cultural indicators": The analysis if mass mediated public message systems. AV Communication Review, 17(2): 137-148. https://link.springer.com/article/10.1007/BF02769102

Goncalves, S. F., \& Gomes, A. R. 2012. Exercising for weight and shape reasons vs. health control reasons: The implication on eating disturbance and psychological functioning. Eating Behaviors, 13(2): 127-130. https://doi.org/10.1016/j.eatbeh.2011.11.011

Goodyear, V. A., Armour, K. M., \& Wood, H. 2018. Young people and their engagement with health-related social media: new perspectives. Sport, Education and Society, 24(7): 673-688. https://doi.org/10.1080/13573322.2017.1423464

Hashmeta. 2018. Social media landscape in Singapore. 2019. Retrieved from https://hashmeta.com/blog/social-media-landscape-in-singapore-2019/. August 8.

Hausenblas, H. 2015. Is "fitspiration" doing more harm than good? Retrieved from http://health.usnews.com/health-news/blogs/eatrun/ 2015/02/09/is-fitspiration-doing-more-harm-than-good?int=9fe908\&src=usn_fb

Hsieh, H.-F., \& Shannon, S. E. 2005. Three Approaches to Qualitative Content Analysis. Qualitative Health Research, 15(9): 1277-1288. https://doi.org/10.1177/1049732305276687

Ho, S., Lee, E., \& Liao, Y. 2016. Social Network Sites, Friends, and Celebrities: The Roles of Social Comparison and Celebrity Involvement in Adolescents' Body Image Dissatisfaction. Social Media + Society, 2(3). https://doi.org/10.1177/2056305116664216

Jong, S., \& Drummond, M. 2016. Exploring online fitness culture and young females. Leisure Studies, 35(6): 758-770. https://doi.or $\mathrm{g} / 10.1080 / 02614367.2016 .1182202$

Julien, H. 2012. Content Analysis. SAGE Research Methods, 121-122. https://dx.doi.org/10.4135/9781412963909.n65

Lavrakas, P. J. (2011). Eligibility. SAGE Research Methods, 231. https://dx.doi.org/10.4135/9781412963947.n158

Lee, H.-R., Lee, H. E., Choi, J., Kim, J. H., \& Han, H. L. 2014. Social Media Use, Body Image, and Psychological Well-Being: A Cross-Cultural Comparison of Korea and the United States. Journal of Health Communication, 19(12): 1343-1358. https://doi. org/10.1080/10810730.2014.904022

Lewallen, J., \& Behm-Morawitz, E. 2016. Pinterest or Thinterest?: Social Comparison and Body Image on Social Media. Social Media Society, 2(1): 205630511664055. https://doi.org/10.1177/2056305116640559

Meraz, S. 2011. The fight for 'how to think': traditional media, social networks, and issue interpretation. Journalism, 12(1): 107-127. https://doi.org/10.1177/1464884910385193

Peebles, R., Wilson, J. L., Litt, I. F., Hardy, K. K., Lock, J. D., Mann, J. R., \& Borzekowski, D. L. G. 2012. Disordered eating in a digital age: Eating behaviors, health, and quality of life in users of websites with pro-eating disorder content. Journal of Medical Internet Research, 14: e148. https://doi.org/10.2196/jmir.2023

Perloff, R. M. 2009. Mass media, social perception, and the third-person effect. Media effects: Advances in theory and research, $252-268$. Retrieved from https://www.taylorfrancis.com/books/e/9780203877111/chapters/10.4324/9780203877111-18

Perrault, E. K., Hildenbrand, G. M., Mccullock, S. P., Schmitz, K. J., \& Dolick, K. N. 2019. Hashtag Health: College Health on Social Media and Students' Motivations to Follow, Interact, and Share Their Social Media Content. Health Promotion Practice, 20(5): 721-729. https://doi.org/ 10.1177/1524839919853820

Perrin, A. 2015. Social Networking Usage: 2005-2015. Pew Research Center. Retrieved from http://www.pewinternet. org/2015/10/08/2015/Social- Networking-Usage-2005-2015/

Potter, W. J., \& Levine $\square$ Donnerstein, D. 1999. Rethinking validity and reliability in content analysis. Journal of Applied Communication Research, 27(3): 258-284. https://doi.org/ 10.1080/00909889909365539

Prichard, I., McLachlan, A. C., Lavis, T., \& Tiggemann, M. 2017. The Implication of Different Forms of \#fitspiration Imagery on Body Image, Mood, and Self-Objectification among Young Women. Sex Roles, 78(11-12), 789-798. https://doi.org/10.1007/ s11199-017-0830-3

Raggatt, M., Wright, C. J. C., Carrotte, E., Jenkinson, R., Mulgrew, K., Prichard, I., \& Lim, M. S. C. 2018. "I aspire to look and feel healthy like the posts convey": engagement with fitness inspiration on social media and perceptions of its influence on health and wellbeing. BMC Public Health, 18(1). https://doi.org/10.1186/s12889-018-5930-7

Richard, M. P. 2014. Social media effects on young women's body image concerns: theoretical perspectives and an agenda for research. Sex Roles, 71: 363-377. https://doi.org/10.1007/s11199-014-0384-6

Robinson, L., Prichard, I., Nikolaidis, A., Drummond, C., Drummond, M., \& Tiggemann, M. 2017. Idealised media images: The effect of fitspiration imagery on body satisfaction and exercise behaviour. Body Image, 22: 65-71. https://doi.org/10.1016/j. bodyim.2017.06.001

Rutherford-Hemming, T. 2018. Pilot Studies. SAGE Research Methods, 1254. https://dx.doi.org/10.4135/9781506326139.n518

Schaefer, L. M., Burke, N. L., Thompson, J. K., Dedrick, R. F., Heinberg, L. J., Calogero, R. M., ... \& Swami, V. 2015. Development and validation of the Sociocultural Attitudes Towards Appearance Questionnaire-4 (SATAQ-4). Psychological Assessment, 27: 54-67.

Schreiber, J. B. 2012. Descriptive Statistics. SAGE Research Methods, 210-212.

Simpson, C., \& Mazzeo, S. 2017. Skinny Is Not Enough: A Content Analysis of Fitspiration on Pinterest. Health Communication, 32(5): 560-567. https://doi.org/10.1080/10410236.2016.1140273

Shahari, F. 2019. 10+ interesting social media statistics 2019. Retrieved from https://cloudrock.asia/sg/blog/social-media-statistics-singapore/

Talaverna, M., (2015). 10 reasons why influencer marketing is the next big thing. Retrieved from http://www.adweek.com/digital/ 10-reasons-why-influencermarketing-is-the-next-big-thing/

Tiggemann, M., \& Barbato, I. 2018. "You look great!": The effect of viewing appearance-related Instagram comments on women's body image. Body Image, 27: 61-66. https://doi.org/10.1016/j.bodyim.2018.08.009

Tiggemann, M., \& Zaccardo, M. 2015. "Exercise to be fit, not skinny": The effect of fitspiration imagery on women's body image. Body Image, 15: 61-67. http://doi.org/10.1016/j.bodyim.2015.06.003

Uy, G. F. 2019. 6 Singapore social media stats marketers should know. Techinasia.com. Retrieved from https://www.techinasia.com/ singapore-social-media-stats

Waterfield, J. 2018. Convenience Sampling. SAGE Research Methods, 403. https://dx.doi.org/10.4135/9781506326139.n155Disciplines: Education

Wiklund, E., Jonsson, E., Coe, A.-B., \& Wiklund, M. 2017. 'Strong is the new skinny': navigating fitness hype among teenagers in northern Sweden. Sport, Education and Society, 24(5): 441-454. http://doi.org/10.1080/13573322.2017.1402758 